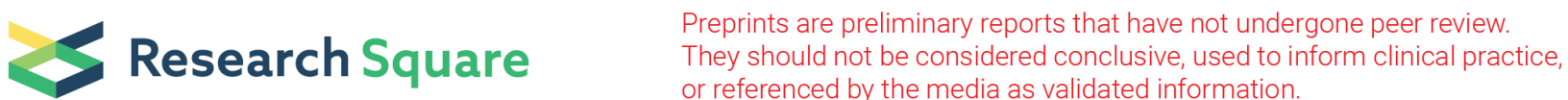

\section{Cholera Outbreak Caused by Drinking Unprotected Well Water Contaminated with Feces from an Open Storm Water Drainage - Kampala City, Uganda, January 2019}

Daniel Eurien ( $\nabla$ euriend56@gmail.com )

Makerere University College of Health Sciences https://orcid.org/0000-0003-2356-5349

Bernadette Basuta Mirembe

Makerere University Faculty of Medicine: Makerere University College of Health Sciences

Angella Musewa

Makerere University College of Health Sciences

Esther Kisaakye

Makerere University College of Health Sciences

Benon Kwesiga

Makerere University CHS: Makerere University College of Health Sciences

Francis Ogole

Republic of Uganda Ministry of Health

Daniel Okello Ayen

Kampala Capital City Authority

Daniel Kadobera

Makerere University Faculty of Medicine: Makerere University College of Health Sciences Lilian Bulage

Makerere University Faculty of Medicine: Makerere University College of Health Sciences Alex Riolexus Ario

Makerere University Faculty of Medicine: Makerere University College of Health Sciences

Bao-Ping Zhu

US Centers for Disease Control and Prevention, Kampala, Uganda

Research article

Keywords: Cholera, Outbreak, Capital City, Uganda

Posted Date: November 2nd, 2020

DOI: https://doi.org/10.21203/rs.3.rs-99547/v1

License: @ (1) This work is licensed under a Creative Commons Attribution 4.0 International License. Read Full License 


\section{Abstract}

Background: Kampala city slums, with one million dwellers living in poor sanitary conditions, frequently experience cholera outbreaks. On 6 January 2019, Lubaga Division notified the Uganda Ministry of Health of a suspected cholera outbreak in Sembule village. We investigated to identify the source and mode of transmission, and recommend evidence-based interventions.

Methods: We defined a suspected case as onset of profuse, painless, acute watery diarrhoea in a Kampala City resident ( $\geq 2$ years) from 28 December 2018 to 11 February 2019. A confirmed case was a suspected case with Vibrio cholerae identified from the patient's stool specimen by culture or Polymerase Chain Reaction (PCR). We found cases by record review and active community case-finding. We conducted a case-control study in Sembule village, the epi-center of this outbreak, to compare exposures between confirmed case-persons and asymptomatic controls, individually matched by age group. We overlaid rainfall data with the epidemic curve to identify temporal patterns between rain and illnesses. We conducted an environmental assessment, interviewed village local council members, and tested water samples from randomly-selected households and water sources using culture and PCR to identify $V$. cholerae.

Results: We identified 50 suspected case-patients, with three deaths (case-fatality rate: $6.0 \%$ ). Of 45 case-patients with stool samples tested, 22 were confirmed positive for $V$. cholerae 01, serotype Ogawa. All age groups were affected; persons aged 5-14 years had the highest attack rate (AR) (8.2/100,000). The epidemic curve showed several point-source outbreaks; cases repeatedly spiked immediately following rainfall. Sembule village had a token-operated water tap, which had broken down one month before the outbreak, forcing residents to obtain water from one of three wells (Wells A, B, C) or a public tap. Environmental assessment showed that residents emptied their feces into a drainage channel connected to Well $\mathrm{C}$. Drinking water from Well $\mathrm{C}$ was associated with illness $\left(\mathrm{OR}_{\mathrm{M}-\mathrm{H}}=21,95 \% \mathrm{Cl}\right.$ : 4.6-93). Drinking water from a public tap $\left(\mathrm{OR}_{\mathrm{M}-\mathrm{H}}=0.33,95 \% \mathrm{Cl}: 0.13-0.86\right)$ and drinking boiled water $\left(\mathrm{OR} \mathrm{M}_{\mathrm{H}}=0.15,95 \% \mathrm{Cl}\right.$ : 0.036-0.59) were protective. Water from a container in one of eight households sampled tested positive for $V$. cholerae, water from Well $\mathrm{C}$ had coliform counts 冈900/100ml.

Conclusions: Drinking contaminated water from an unprotected well was associated with this cholera outbreak. We recommended emergency chlorination of drinking water, fixing the broken token tap, and closure of Well C.

\section{Background}

Cholera is an acute diarrheal infection that is characterized by sudden onset of profuse, painless watery diarrhea and vomiting (1). It can rapidly lead to severe dehydration and death if left untreated (2). With timely and proper management, the case-fatality rate should be $<1 \%$ (3). Infection occurs when food or water contaminated with the bacterium Vibrio cholerae serogroups 01 and 0139 are ingested. Epidemics have been exclusively associated with the toxigenic $V$. cholerae 01 serogroup, which consists of two biotypes: classical and El Tor. Each biotype comprises 3 serotypes: Inaba, Ogawa, and Hikojima (4).

It is estimated that 1.4 to 4.3 million cholera cases and 28,000 to 142,000 cholera-related deaths occur every year globally (2). Access to clean water and food is associated with reduced disease incidence (2). In recent years, cholera outbreaks have mainly occurred in developing countries, particularly in poor areas with inadequate access to clean water and poor sanitation in Sub-Saharan Africa (6). In 2019, the World Health Organization (WHO) categorized Uganda among the 51 "endemic" countries for cholera (those reporting confirmed cases during the last 3 years with evidence of local transmission) (2).

Uganda has several cholera hotspots, most along the western border with the Democratic Republic of Congo, in Karamoja region to the north, and in Kampala city slums (7). Kampala city, like most cities in developing countries, is experiencing rapid urbanization as well as rapid development of informal peri-urban settlements, or slums. More than $60 \%$ of the city's low-income population resides in these densely-populated slums, which have very low levels of basic services (sanitation, water supply, solid waste collection, and storm water disposal) (8)(9). Most slums in Kampala are situated in low-lying areas, making them susceptible to frequent flooding during heavy rains. The use of pit latrines, the dominant sanitary facilities in the Kampala slums, results in constant risk of fecal contamination of shallow groundwater, which is frequently used as a drinking water source $(9,10)$. Despite being prohibited since 2000 , pit latrines are still constructed along drainage channels, where they can release sewage into open drainage lines (11).

On 6 January 2019, the District Surveillance Officer Lubaga division in Kampala notified the Emergency Operation Center (EOC) of the Ministry of Health $(\mathrm{MoH})$ about a suspected cholera outbreak in Sembule village, a slum in Lubaga division. We investigated to confirm the outbreak, identify the source and mode of transmission, and recommend evidence-based interventions to stop the outbreak and prevent future outbreaks.

\section{Methods Outbreak area}

The outbreak occurred in Kampala (the capital city of Uganda), which has an estimated population of 1.6 million (8)(11). Kampala has five divisions: Kampala Central, Kawempe, Makindye, Lubaga, and Nakawa. We focused our epidemiologic investigation in Sembule village, in Kabowa parish in Lubaga Division (Fig. 1). The village is located on a swamp and was the epi-center of this outbreak. As of January 2019 , the village register listed 780 households and a population of approximately 4,700 persons. A large proportion of the community comprises mobile persons who conduct petty trade such as vending vegetables and fruits in Kampala city center. One of the city's major open drainage channels, Nalukolongo channel, passes through the village. The main sources of drinking water in Sembule village include a public token tap, private taps, and open wells. The public token tap is a pre-paid water meter that dispenses low-cost safe water to households, and was associated with a pilot program supported by the National Water and Sewerage Corporation (NWSC) and donors starting in 2015 in Kampala slums. The meters are operated by an electronic key, known as a token, that is pre-loaded with credit. Any person can buy a key and refill the token with credit at a cost of 0.01 United States Dollar (USD) per 20-liter jerry can. As water is dispensed, the meter deducts credit from the token at the official rate. In this way, consumers deal directly with NWSC and this eliminates middlemen from inflating safe water prices.

Page 2/9 


\section{Case definition and case-finding}

We defined a suspected case as onset of profuse, painless, acute watery diarrhea in a Kampala City resident ( $\geq 2$ years) from 28 December 2018 to 11 February 2019. A confirmed case was a suspected case with Vibrio cholerae identified from the patient's stool specimen by culture or PCR. We reviewed patient records at Naguru Hospital, Lubaga hospital, and Mulago National Referral Hospital to identify suspected case-patients. These three hospitals were designated by $\mathrm{MoH}$ to provide cholera diagnostic testing and treatment free of charge to patients from the affected areas. With help from the community health workers, we actively searched for additional cases in households and private clinics in the affected areas.

\section{Descriptive epidemiology and hypothesis generation}

We performed descriptive analysis on case-patients' clinical presentations, as well as distribution of the case-patients by age, sex, and place of residence. We used village population data from the Local Council chairperson's village register as the denominator to calculate attack rates. We used epidemic curves to describe case-patients' dates of symptom onset. We also calculated the case-fatality rate.

To generate hypotheses on possible exposures associated with illness, we interviewed 23 case-patients from the most affected village. We asked casepatients about the type and source of food they ate and the source of the water they drank during the five days before their symptom onset.

\section{Case-control study}

To test the generated hypothesis, we conducted a case-control study in Sembule village, where the first cases were reported. We generated a list of all households with a confirmed case-patient, and selected one from each of the 18 affected households. In households with more than one case, we wrote names of the affected persons on paper lots, shuffled in a bowl and picked one. For each case-patient, we selected five control-persons. A control-person was a resident of Sembule village within the same 5-year age-group as the case-patient and without acute watery diarrhea from 28 December 2018 to the time of the investigation. To select control-persons, we obtained a list of households in the village with eligible control-persons, and wrote the names of the household heads on paper lots. We randomly drew out five paper lots from the basket, and attempted to identify an eligible control-person from each of the selected households. If enough control-persons were not identified, we repeated the process until we had enough control-persons for each case.

We administered a questionnaire to the eligible case-patients and control-persons to obtain information on their water exposures. Data were collected on the respondents' water source, means of storage (jerrycan or open container), whether respondents had a water token or not, whether the respondents treated (using chlorine tablets) or boiled their drinking water, and demographic variables (i.e., age, sex, education level). To measure the associations between exposure variables and illness status, we used the Mantel-Haenszel method to estimate odds ratios (OR) and their $95 \%$ confidence intervals, accounting for frequency-matching of case-persons and control-persons.

\section{Laboratory investigations}

Stool samples from 45 case-patients admitted at the three Cholera Treatment Centers (CTCs) were screened using the rapid immunochromatographic diagnostic test Crystal VC ${ }^{\text {TM }}$ dipstick (Span Diagnostics Ltd., Surat, India). Approximately 4-6 drops of liquid stool were transferred to a test tube using a pipette that was part of the dipstick package. The dipstick was then inserted into the liquid stool, and the results were read after approximately 15 min. We interpreted results following the manufacturer's instructions, using the standard manufacturer's procedure (12) (13). We also transported stool samples from the 45 case-patients in Cary-Blair medium to the Central Public Health Laboratory for culture. The swabs were first cultured on Thiosulphate-Citrate-Bile-Salts Sucrose (TCBS ${ }^{\text {TM }}$; EIKEN Japan) agar inoculated in alkaline peptone water at 37 degrees Celsius for $18-24 \mathrm{~h}$ (15). Upon identification, $\mathrm{V}$. cholerae isolates were further evaluated to ascertain the serogroup and serotype by agglutination with Polyvalent 01 and monospecific Ogawa and Inaba antisera.

\section{Environmental investigations}

Based on results from our hypothesis-generating interviews and descriptive epidemiology, we suspected that drinking contaminated water might have been associated with this outbreak. We therefore inspected the main sources of drinking water in Sembule village, including the public token tap, private taps, and open wells. We drew map of the village area using Quantum GIS to show the major sources of water and distribution of cholera case-households. We systematically collected water samples from six public token taps, one household water tap, four open wells, and water storage containers in six randomlyselected households in Sembule village using sterile containers. We used conventional bacteriological culture methods to attempt to identify $V$. cholerae in water sources (14)(15). We obtained rainfall data for Kampala city around the outbreak period from World Weather Online (16) to establish the temporal association of rain with case counts. We verified the rainfall dates by interviewing the Village Local Council leader and community health workers about the days it rained and any resulting flooding.

\section{Results}

\section{Descriptive epidemiology and hypothesis generation findings}

We identified 50 suspected cholera case-patients as of 11 February 2019 with three deaths (case-fatality rate $=6 \%$ ). Cases presented with watery diarrhea (100\%), vomiting (68\%), abdominal pain (12\%), and fever (5.8\%).

The median age of case-patients was 20 years; with the most affected age-group 5-14 years. Females and males were similarly affected (Table 1). The epidemic curve showed several point-source outbreaks (Fig. 2). 
Table 1

Attack rates by age-group and sex of cholera case-patients during a cholera outbreak: Kampala City, Uganda, December 2018 to February

\begin{tabular}{|llll|}
\hline \multicolumn{4}{|c|}{2019.} \\
\hline Characteristic & Number(n= 50) & Population & Attack Rate/100,000 \\
\hline Age-group & & & \\
$<5$ & 2 & 225,140 & 0.88 \\
\hline $5-14$ & 25 & 304,540 & 8.2 \\
\hline $15-24$ & 14 & 459,630 & 3 \\
$\geq 25$ & 9 & 621,190 & 1.4 \\
\hline Sex & & & \\
\hline Male & 24 & 762,700 & 3.1 \\
Female & 26 & 862,700 & 3 \\
\hline
\end{tabular}

All five divisions of Kampala, including Kampala Central, Kawempe, Makindye, Lubaga, and Nakawa were affected (Fig. 1 inset), with Lubaga division being the most affected (AR: 6.5/100,000) followed by Central Division (AR: 2.1/100,000). All affected case-patients in Lubaga division came from Sembule village, where the first cases were reported (Fig. 3).

Meteorological data showed that the peaks of the cholera outbreak were preceded by heavy rainfall (Fig. 2). Following declaration of the outbreak on 10 January 2019, the $\mathrm{MoH}$ implemented a number of interventions, including community awareness campaigns and distribution of chlorine to households, the number of cases reduced after subsequent rainfall. There were no new cases following blockage of Well C outlets by the Village Local Council on 3 February 2019.

Case-patients reported obtaining water from 10 sources in total, including one private tap, six token taps, and three wells. Of the 23 case-patients interviewed, $22(96 \%)$ had consumed water from Well $C$ within the five days before symptom onset; all 22 reported that they did not boil the water. Well $C$ was an unprotected well with water coming from an underground aquifer and an outlet pipe draining directly into the shallow well. Wells $A$ and $B$ were privately-owned protected wells, and the six token taps and private tap were connected to the NWSC and therefore protected (Fig. 3). No single common food was reported eaten by the case-patients during the same period before onset of symptoms. We therefore hypothesized that drinking unboiled water from unprotected Well $\mathrm{C}$ was associated with the cholera outbreak.

\section{Case-control study findings}

We evaluated water sources alone and in combination, for persons who reported using more than one water source, for their association with illness. All combinations of water sources that included any water from Well C were associated with illness, while all water sources that did not involve water from Well C were neutral or protective (Table 2).

Table 2

Distribution of exposure status among case-patients and control persons during a cholera outbreak in Kampala between December 2018 and January 2019.

\begin{tabular}{|c|c|c|c|}
\hline \multirow[t]{2}{*}{ Exposure } & \multicolumn{2}{|l|}{$N(\%)$ exposed } & \multirow[t]{2}{*}{$\mathrm{aOR}_{\mathrm{M}-\mathrm{H}}(95 \% \mathrm{Cl})$} \\
\hline & Cases $(n=18)$ & Controls $(n=90)$ & \\
\hline Drank water from Well C only & $15(83)$ & $16(18)$ & $21(4.6-93)$ \\
\hline Drank water both from token tap \&Well C & $10(56)$ & $20(22)$ & $8.5(2.0-36)$ \\
\hline Drank water from both token tap \& Well B & $1(5.6)$ & $5(5.6)$ & $1.0(0.12-9.1)$ \\
\hline Drank water from Well B only & $1(5.6)$ & $6(6.7)$ & $0.83(0.11-6.6)$ \\
\hline Drank water from token tap & $5(28)$ & $62(69)$ & $0.33(0.13-0.86)$ \\
\hline Drank water from Well A only & $0(0)$ & $6(6.7)$ & 0 (0-undefined) \\
\hline Drank water from both token tap \& Well A & $0(0)$ & $6(7.1)$ & 0 (0-undefined) \\
\hline Boiled water before drinking & $6(33)$ & $59(66)$ & $0.15(0.04-0.60)$ \\
\hline
\end{tabular}

\section{Laboratory investigation and environmental assessment findings}

Of the 45 stool samples collected from suspected case-patients, 22 were culture-positive for $V$. cholerae 01, biotype El Tor serotype Ogawa.

Water testing identified no coliforms (Most Probable Number [MPN] 0/100 ml) in samples from public stand water taps and private taps, which is Uganda's standard for safe drinking water from treated water entering the distribution systems (0 MPN/100 ml) (17). Samples collected from Well C had total coliform 
counts $₫ 900 \mathrm{MPN} / 100 \mathrm{ml}$. Water from Well $\mathrm{C}$ was above the $<10 \mathrm{MPN} / 100 \mathrm{ml}$ threshold for un-piped water supplies (17). Of six stored water samples from six households tested, three (50\%) had a total coliform count of $\geq 500 \mathrm{MPN} / 100 \mathrm{ml}$. The sample obtained from stored water sample from one household tested positive by PCR for V. cholerae 01, biotype El Tor serotype Ogawa.

We established that, of the 23 case-patients in Sembule Village, 20 (87\%) had previously accessed water from one public token tap, for which they paid United States Dollar (USD) 0.01 per 20-liter jerrycan. However, the tap broke down in December 2018, forcing residents to identify other sources of water. While water from Well C was free, a 20-liter jerry can from Wells A and B cost USD 0.08, and the same volume cost USD 0.13 from private household taps.

Well C comprised a small, shallow, unconfined outlet for water coming from a below-ground aquifer. Water flowed into Well C from a pipe fitted perpendicular to the outlet, just above the surface (Fig. 4). The well did not have a permanent cover and the water was flowing continuously into the well from the aquifer. The output pipe from unprotected Well $\mathrm{C}$ was approximately $0.3 \mathrm{~m}$ above the bottom of an open, informal drainage channel. Most of the community pit latrines were constructed along the drainage channel, to facilitate disposal of waste. Community members often dumped fecal matter into the drainage channel when it rained, to facilitate the washing-away of the waste. Flooding of the drainage channel that resulted from the rain water mixed with the contents of the drainage channel and allowed flow into other nearby areas, including the outlet pipe of unprotected Well $\mathrm{C}$. We found evidence of release of fecal matter into the drainage channel from at least one of the pit latrines constructed along the drainage channel.

\section{Discussion}

Our investigation revealed that a cholera outbreak in Sembule village was associated with drinking unprotected well water. A month before this outbreak, there were reported unconfirmed cholera outbreaks in the neighboring Kisenyi village. Cholera might have been introduced into Sembule village by one or multiple visitors carrying the bacteria, causing the initial contamination when feces were released from their pit latrines into the drainage channel, a common practice in slum areas where latrines are emptied into open drainages during heavy rains. Heavy rainfall likely washed feces in drainage channels into the wells, contaminating the water, which was subsequently consumed without boiling by case-patients in this outbreak.

Globally, poor water and sanitation conditions are often implicated in disease outbreaks, particularly outbreaks of typhoid and cholera (18)(19)(20)(21). These outbreaks are often precipitated or exacerbated by rains (24)(25)(26). Cities in Sub-Saharan Africa are at particularly high risk due to recent population growth without a concomitant increase in access to improved water and sanitation facilities (22)(23). Previous cholera outbreaks in Kampala city occurred in slum dwellings characterized by overcrowding, insufficient clean water, and poor sanitation facilities (14)(27), and cholera outbreaks in others parts of Uganda have also been associated with drinking untreated water $(4,13-16)$. Contamination of the water in such outbreaks has frequently resulted from poor urban planning by city authorities that allowed the development of informal settlements without adequate water and sanitation facilities, and inadequate enforcement of the Public Health Act in slum areas (28).

Many cholera outbreaks in Uganda have not been investigated epidemiologically, and most die out after the implementation of general interventions (29). The inability to investigate past outbreaks presents a missed opportunity to generate specific evidence-based interventions that, if implemented, might have helped prevent subsequent outbreaks. Results from our investigation provided actionable evidence on the ways well water may be contaminated following release of fecal matter from latrines after rains. We were also able to demonstrate the security of the public piped water system, which remained uncontaminated throughout this outbreak. These data led Kampala Capital City Authority and Ministry of Health to carry out interventions, including distribution of chlorine tablets to household for water disinfection, desilting of the drainage channels to prevent future flooding, treatment of cases, and health education in the communities.

We were unable to identify the initial source of contamination in this outbreak. Identifying the index case can be difficult in cholera outbreaks, as many infected persons are asymptomatic, yet still shed bacteria in their stool (30). However, definitive identification of the index case in this area might have enabled the provision of more specific recommendations for future prevention.

\section{Conclusions And Recommendations}

In conclusion, this was a cholera outbreak in an urban slum associated with drinking contaminated well water. Fecal contamination of well water likely resulted from the practice of emptying pit latrines into drainage channels during heavy rainfalls. The following public health actions were taken to contain the outbreak: the Ministry of Health distributed chlorine tablets for household water disinfection 9 January 2019, Kampala Capital City Authority emptied pit latrines in Sembule village from 15 to 30 January 2019, the village local council closed Well C on 3 February 2019, and we provided health education to Sembule village residents on prevention of cholera. We recommended treatment and boiling of drinking water. We also recommended increasing the number of public token taps to increase access to safe water, enforcement of Chap. 281 of the Public Health Act, and provision of inexpensive latrine-emptying options to dissuade people from releasing fecal matter into open drainages. In addition, to sustainably address the cholera outbreaks in crowded urban settings, Uganda needs to make significant investments in safe water, sanitation and hygiene as prescribed in the End Cholera-Global Roadmap to 2030 .

\section{Abbreviations}

CDC: United States Centers for Disease Control and Prevention, MoH: Ministry of Health, WHO: World Health Organization, Cl: Confidence interval,

CPHL: Central Public Health Laboratory, OR: Odds ratio, OR ${ }_{M-H}$ : Mantel-Haenszel adjusted ORs

\section{Declarations}

Ethics approval and consent to participate 
This investigation was authorized by the Uganda Ministry of Health in response to a public health emergency and was, therefore, determined to be exempt from institutional review. It was also determined by the Office of the Associate Director for Science at the Center for Global Health, US Centers for Disease Control and Prevention, that this study did not involve human subjects and that its primary intent was public health practice or disease control activity (specifically, epidemic or endemic disease control activity). Verbal informed consent was obtained from the participants or, if the interviewee was a minor, guardians before the start of each interview. Written consent could not be obtained because it was impractical as most of the participants were illiterate.

However, the purpose of the investigation was explained to all participants. Participants were also informed that their involvement was entirely voluntary and their refusal to answer any or all of the questions would not result in any negative consequences. We referred all cases identified in the community to the designated treatment centers for treatment.

\section{Consent for publication}

Not applicable

\section{Availability of data and materials}

The study datasets upon which our findings are based belong to the Uganda Public Health Fellowship Program. For confidentiality reasons, the datasets are not publicly available. However, the data sets can be availed upon reasonable request from the corresponding author and with permission from the Uganda Public Health Fellowship Program.

\section{Competing interests}

The authors declare that they have no competing interests.

\section{Funding}

Authors were funded by their respective organizations. This project was also supported by the President's Emergency Plan for AIDS Relief (PEPFAR), through the US CDCs Cooperative Agreement number GH001353-01 through Makerere University School of Public Health to the Uganda Public Health Fellowship Program, Ministry of Health. Its contents are solely the responsibility of the authors and do not necessarily represent the official views of the PEPFAR, US Centers for Disease Control and Prevention, Makerere University School of Public Health, or the Ministry of Health of Uganda.

\section{Authors' contributions}

DE was involved in the conceptualization, design, implementation and writing the manuscript. MBB, AM, EK, FO, AO were involved in the design and implementation of the investigation. DE, AM and EK were involved in the data analysis. DK, BK, LB, ARA and BPZ had primary responsibility for final content. All authors participated in the writing, read and approved the final manuscript.

\section{Acknowledgements}

We would like to thank the Kampala Capital City Authority officials, Ministry of Health team and the Village Health Teams for their roles in facilitating data collection and contributions to ending the outbreak. We also acknowledge the numerous personnel from the Central Public Health Laboratories who helped with laboratory testing of cases and water samples and crucially the medical teams at Mulago National Referral Hospital and Naguru Regional Referral Hospital for managing the cases we referred to them.

\section{Disclaimer}

The maps depicted in the manuscript are my own and were drawn specifically for this project.

\section{References}

1. Cholera key facts. World Health Organization. 2018 [Internet]. [cited 2019 Feb 12]. Available from: https://www.who.int/news-room/factsheets/detail/cholera

2. World Health Organisation cholera fact sheet [Internet]. [cited 2019 Jan 14]. Available from: https://www.who.int/news-room/fact-sheets/detail/cholera

3. WHO | Cholera case fatality ratio (\%) [Internet]. WHO. [cited 2019 Jan 14]. Available from: https://www.who.int/gho/epidemic_diseases/cholera/situation_trends_case_fatality_ratio/en/

4. Faruque SM, Albert MJ, Mekalanos JJ. Epidemiology, Genetics, and Ecology of ToxigenicVibrio cholerae. Microbiol Mol Biol Rev. 1998 Dec 1;62(4):130114.

5. Diagnosis and Detection | Cholera | CDC [Internet]. 2018 [cited 2019 Jan 14]. Available from: https://www.cdc.gov/cholera/diagnosis.html

6. Ang GY, Yu CY, Balqis K, Elina HT, Azura H, Hani MH, et al. Molecular Evidence of Cholera Outbreak Caused by a Toxigenic Vibrio cholerae 01 El Tor Variant Strain in Kelantan, Malaysia. J Clin Microbiol. 2010 Nov 1;48(11):3963-9.

7. Bwire G, Malimbo M, Maskery B, Kim YE, Mogasale V, Levin A. The Burden of Cholera in Uganda. PLoS Negl Trop Dis [Internet]. 2013 Dec 5 [cited 2019 Jan 14];7(12). Available from: https://www.ncbi.nlm.nih.gov/pmc/articles/PMC3855006/

8. 2014 National Census Main Report.pdf [Internet]. [cited 2019 Jan 21]. Available from: http://www.ubos.org/onlinefiles/uploads/ubos/NPHC/2014\%20National\%20Census\%20Main\%20Report.pdf 
9. Kulabako RN, Nalubega M, Wozei E, Thunvik R. Environmental health practices, constraints and possible interventions in peri-urban settlements in developing countries - a review of Kampala, Uganda. Int J Environ Health Res. 2010 Aug 1;20(4):231-57.

10. Katukiza AY, Ronteltap M, Oleja A, Niwagaba CB, Kansiime F, Lens PNL. Selection of sustainable sanitation technologies for urban slums-a case of Bwaise III in Kampala, Uganda. Sci Total Environ. 2010 Dec 1;409(1):52-62.

11. Uganda's District population projections 2015-2020. - Data dot UG [Internet]. [cited 2019 Mar 11]. Available from: http://catalog.data.ug/dataset/ugandas-district-population-projections-2015-2020

12. Ley B, Khatib AM, Thriemer K, von Seidlein L, Deen J, Mukhopadyay A, et al. Evaluation of a Rapid Dipstick (Crystal VC) for the Diagnosis of Cholera in Zanzibar and a Comparison with Previous Studies. PLoS ONE [Internet]. 2012 May 25 [cited 2019 Feb 12];7(5). Available from: https://www.ncbi.nlm.nih.gov/pmc/articles/PMC3360732/

13. Nato F, Boutonnier A, Rajerison M, Grosjean P, Dartevelle S, Guénolé A, et al. One-Step Immunochromatographic Dipstick Tests for Rapid Detection of Vibrio cholerae 01 and 0139 in Stool Samples. Clin Diagn Lab Immunol. 2003 May;10(3):476-8.

14. Huq A, Haley BJ, Taviani E, Chen A, Hasan NA, Colwell RR. Detection, Isolation, and Identification of Vibrio cholerae from the Environment. Curr Protoc Microbiol. 2012 Aug;CHAPTER:Unit6A.5.

15. Ballance R, Bartram J, editors. Water Quality Monitoring: A Practical Guide to the Design and Implementation of Freshwater Quality Studies and Monitoring Programmes [Internet]. Spon Press; 1998 [cited 2019 Jan 29]. Available from: https://www.taylorfrancis.com/books/9780203476796

16. Kampala Historical Weather [Internet]. WorldWeatherOnline.com. [cited 2019 Feb 12]. Available from: https://www.worldweatheronline.com/kampalaweather/kampala/ug.aspx

17. Uganda National Bureau of Standards. Potable water - Specification(2014) [Internet]. [cited 2019 Feb 13]. Available from: https://members.wto.org/crnattachments/2015/TBT/UGA/15_0152_00_e.pdf

18. Uthappa CK, Allam RR, Nalini C, Gunti D, Udaragudi PR, Tadi GP, et al. An outbreak of cholera in Medipally village, Andhra Pradesh, India, 2013. J Health Popul Nutr. 2015;33(1):7.

19. Taylor DL, Kahawita TM, Cairncross S, Ensink JH. The impact of water, sanitation and hygiene interventions to control cholera: a systematic review. PLoS One. 2015;10(8):e0135676.

20. Poullis DA, Attwell RW, Powell SC. The characterization of waterborne-disease outbreaks. Rev Environ Health. 2005;20(2):141-149.

21. Piarroux R, Barrais R, Faucher B, Haus R, Piarroux M, Gaudart J, et al. Understanding the cholera epidemic, Haiti. Emerg Infect Dis. 2011;17(7):1161.

22. Dos Santos S, Adams EA, Neville G, Wada Y, de Sherbinin A, Mullin Bernhardt E, et al. Urban growth and water access in sub-Saharan Africa: Progress, challenges, and emerging research directions. Sci Total Environ. 2017 Dec;607-608:497-508.

23. The future of water in African cities. Urban access to water supply and sanitation in Sub-saharan Africa, Background report. The World Bank. [Internet]. [cited 2019 Feb 11]. Available from: http://documents.worldbank.org/curated/en/221391468009994131/pdf/NonAsciiFileName0.pdf

24. Legros D, McCormick M, Mugero C, Skinnider M, Bek'Obita DD, Okware SI. Epidemiology of cholera outbreak in Kampala, Uganda. East Afr Med J. 2000 Jul;77(7):347-9.

25. Alajo So, Nakavuma J, Erume J. Cholera in endemic districts in Uganda during El Niño rains: 2002-2003. Afr Health Sci. 2006 Jun;6(2):93-7.

26. Olago D, Marshall M, Wandiga SO, Opondo M, Yanda PZ, Kanalawe R, et al. Climatic, socio-economic, and health factors affecting human vulnerability to cholera in the Lake Victoria basin, East Africa. Ambio. 2007 Jun;36(4):350-8.

27. Musoke D, Ndejjo R, Halage AA, Kasasa S, Ssempebwa JC, Carpenter DO. Drinking Water Supply, Sanitation, and Hygiene Promotion Interventions in Two Slum Communities in Central Uganda [Internet]. Journal of Environmental and Public Health. 2018 [cited 2019 Feb 11]. Available from:

https://www.hindawi.com/journals/jeph/2018/3710120/

28. Public health act Chapter_281.pdf - Google Search [Internet]. [cited 2019 Jul 23]. Available from: https://www.google.com/search? q=Public+health+act+Chapter_281.pdf\&rlz=1C1CHZL_enUG838UG838\&oq=Public+health+act+Chapter_281.pdf\&aqs=chrome..69i57j33.1993j0j8\&sourcei 8

29. Kwesiga B, Pande G, Ario AR, Tumwesigye NM, Matovu JKB, Zhu B-P. A prolonged, community-wide cholera outbreak associated with drinking water contaminated by sewage in Kasese District, western Uganda. BMC Public Health. 2017 Jul 18;18(1):30.

30. WHO_SurveillanceVaccinePreventable_02_Cholera_R1.pdf https://www.who.int/immunization/monitoring_surveillance/burden/vpd/WHO_SurveillanceVaccinePreventable_02_Cholera_R1.pdf?ua=1

\section{Figures}




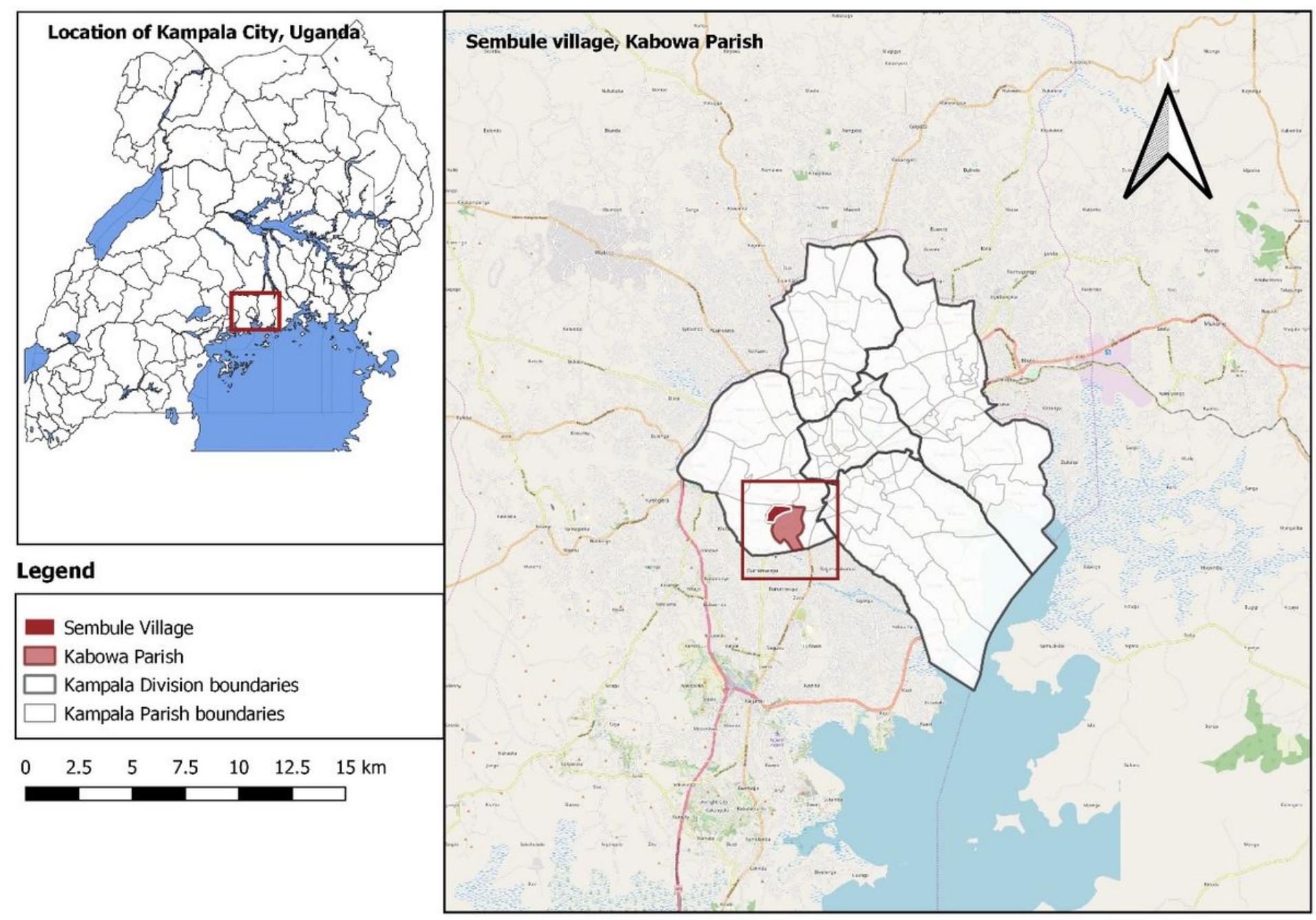

Figure 1

Location of Sembule Village, Kabowa Parish, Kampala City, Uganda. Note: The designations employed and the presentation of the material on this map do not imply the expression of any opinion whatsoever on the part of Research Square concerning the legal status of any country, territory, city or area or of its authorities, or concerning the delimitation of its frontiers or boundaries. This map has been provided by the authors.

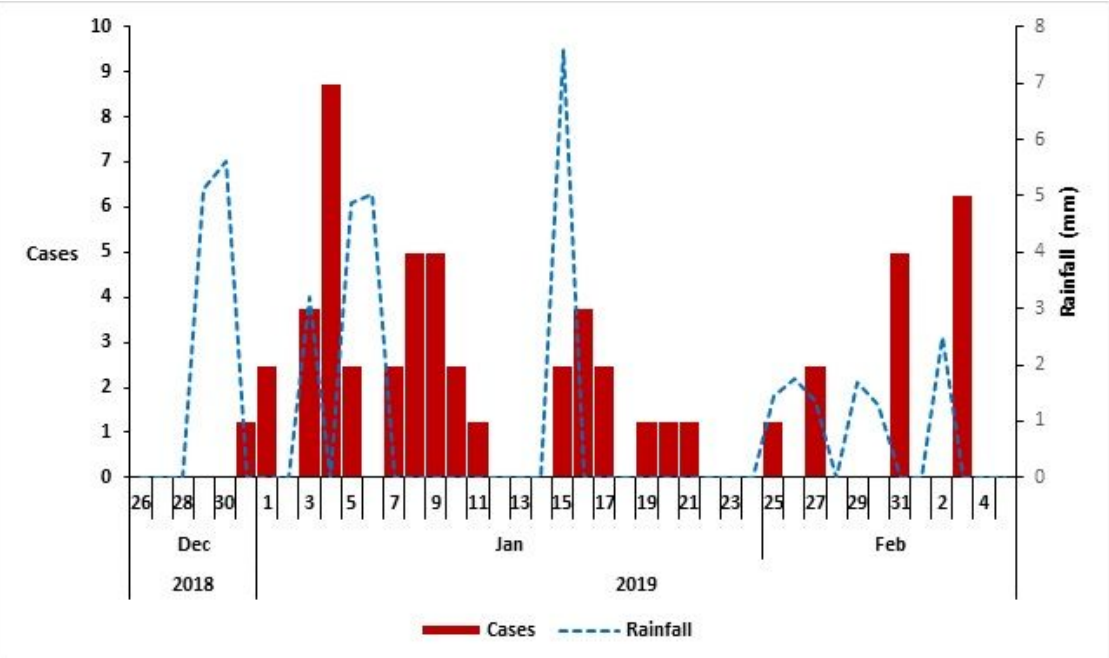

Figure 2

Distribution of symptom onset dates of cholera cases and rainfall: Kampala City, Uganda, December to January 2019. 


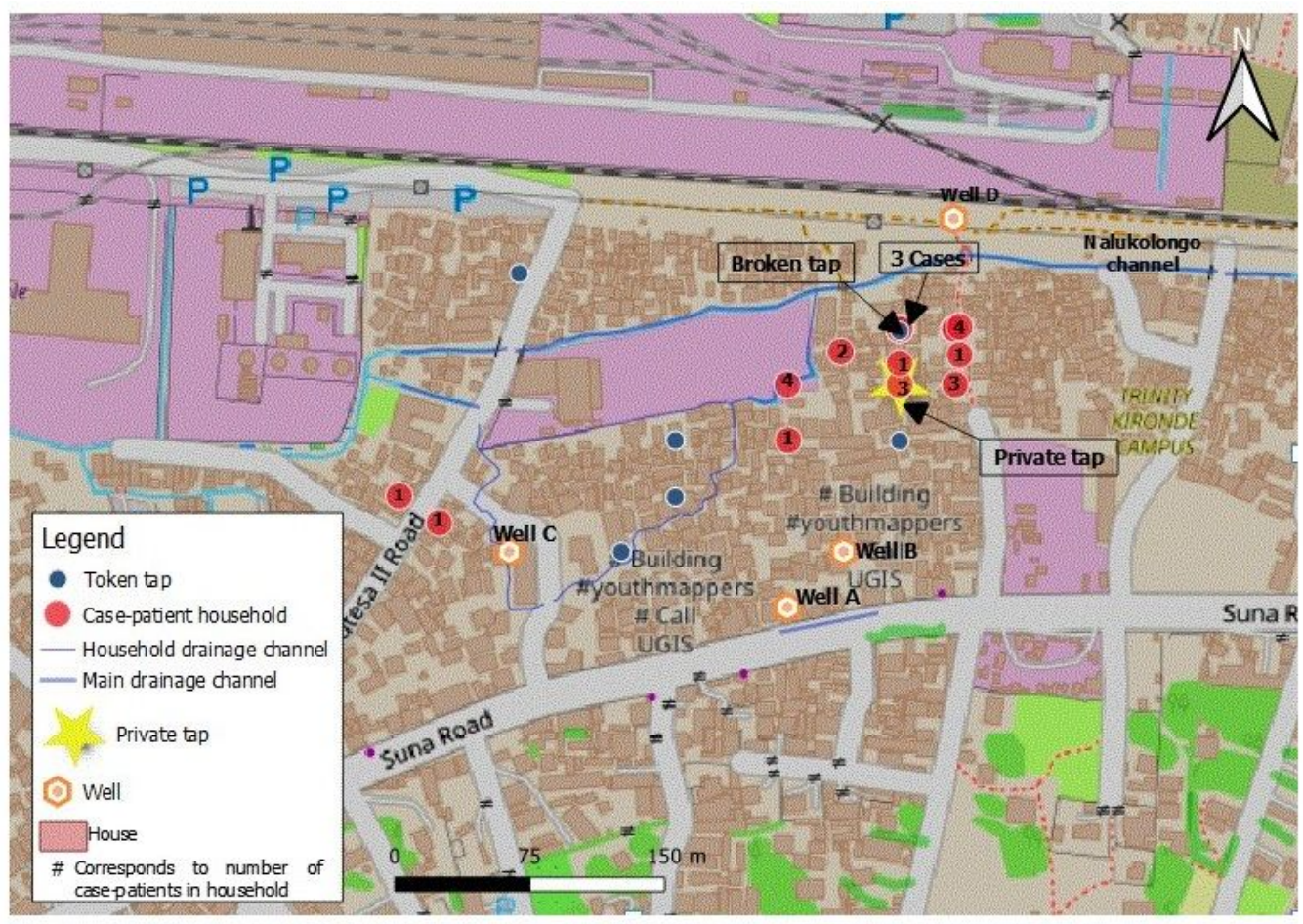

\section{Figure 3}

Map showing location of affected households affected by cholera in Sembule village, Kampala, January 2019. Note: The designations employed and the presentation of the material on this map do not imply the expression of any opinion whatsoever on the part of Research Square concerning the legal status of any country, territory, city or area or of its authorities, or concerning the delimitation of its frontiers or boundaries. This map has been provided by the authors.

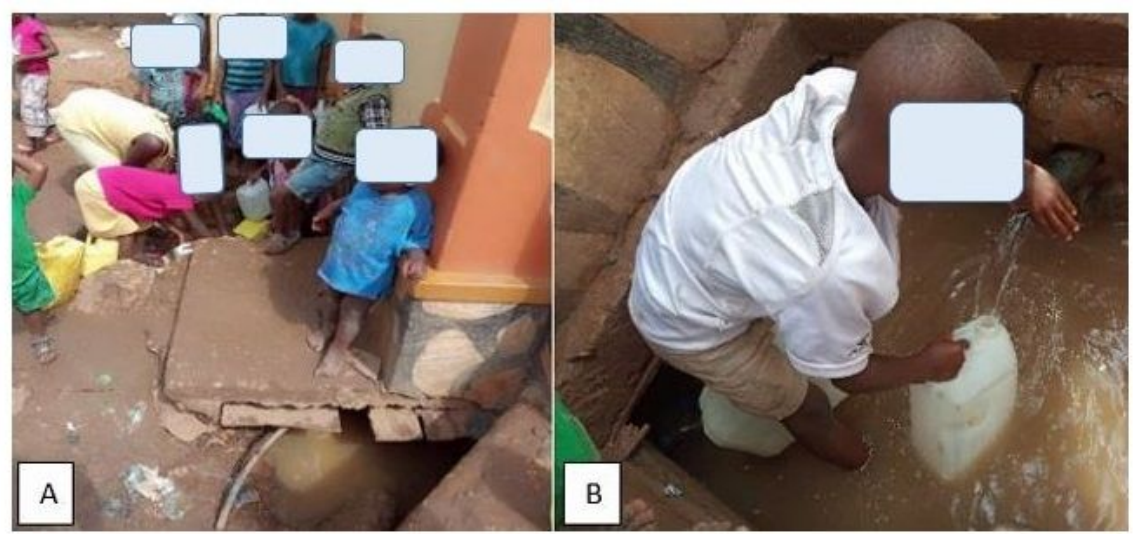

\section{Figure 4}

(A) shows children collecting water from well C; (B) shows the outlet pipe of Well C 